\title{
Influences of renal function descriptors on population pharmacokinetic modeling of vancomycin in Chinese adult patients
}

\author{
Xi-wei $\mathrm{JI}^{1, \#}$, Shuang-min $\mathrm{Jl}^{2, \#}$, Xiao-rong $\mathrm{HE}^{3}$, Xiao $\mathrm{ZHU}^{4}$, Rong $\mathrm{CHEN}^{5}$, Wei $\mathrm{LU}^{5, *}$ \\ ${ }^{1}$ Institute of Clinical Pharmacology, Peking University First Hospital, Beijing 100191, China; ${ }^{2}$ Center for Drug Evaluation, China Food \\ and Drug Administration, Beijing 100038, China; ${ }^{3}$ Department of Pharmacy, Beijing Hospital, Beijing Key Laboratory of Drug Clinical \\ Risk and Personalized Medication Evaluation, Beijing 100730, China; ${ }^{4}$ School of Pharmacy, University of Otago, Dunedin, New \\ Zealand; ${ }^{5}$ Department of Pharmaceutics, School of Pharmaceutical Sciences, Peking University, Beijing 100191, China
}

\begin{abstract}
Vancomycin, a glycopeptide antibiotic for the treatment of grampositive infections, is mainly eliminated via glomerular filtration. Thus, its therapeutic effects are affected predominantly by renal function. The aim of this study was to develop a population pharmacokinetic model of vancomycin for Chinese adult patients and to investigate the influence of different renal function descriptors on the predictability of the model. A retrospective analysis was performed based on the blood concentrations of vancomycin in 218 Chinese adult patients. Among these patients, the data from 160 were used to establish the population pharmacokinetic model, and the data from the remaining 58 patients were used for external model validation. A simulation was employed to determine the appropriate initial vancomycin dosage regimens in adult Chinese patients for reaching the target steady-state trough concentrations of $10-15 \mathrm{mg} / \mathrm{L}$ and $15-20 \mathrm{mg} / \mathrm{L}$. We developed a one-compartment model with first-order absorption to characterize the concentration-time profile of vancomycin. There was a positive correlation between the body clearance of vancomycin and renal function; both creatinine clearance $\left(\mathrm{CL}_{\mathrm{Cr}_{r}}\right)$ and age were the covariates that influenced the $\mathrm{PK}$ of vancomycin, and the excretion of vancomycin decreased as renal function diminishing with age. The typical clearance $(\mathrm{CL})$ value was $2.829 \mathrm{~L} / \mathrm{h}$ for 75 -year-old patients with $\mathrm{CL}_{\mathrm{cr}}$ values of $80 \mathrm{~mL} / \mathrm{min}$, and the rate constant of $\mathrm{CL}$ with the $\mathrm{CL}_{\mathrm{Cr}}$ changing at $1 \mathrm{~mL} / \mathrm{min}$ was 0.00842 . The influence coefficient of age on $\mathrm{CL}$ was 0.08143 . The external validation results revealed that the current different descriptors of renal function behaved similarly to the predicted performance of the models. In conclusion, the developed model is appropriate for Bayesian dose predictions of vancomycin concentrations in the population of Chinese adult patients. Furthermore, the simulation provides a reference for clinical optimized antibacterial therapy with vancomycin.
\end{abstract}

Keywords: vancomycin; population pharmacokinetics; Chinese adult patients; renal function; creatinine; glomerular filtration rate (GFR); NONMEM

Acta Pharmacologica Sinica (2018) 39: 286-293; doi: 10.1038/aps.2017.57; published online 24 Aug 2017

\section{Introduction}

Vancomycin is an effective glycopeptide antibiotic for grampositive infections and is widely used to treat patients with methicillin-resistant Staphylococcus aureus (MRSA), Staphylococcus epidermidis or Enterococcus faecalis ${ }^{[1,2]}$. Vancomycin has moderate side-effects, such as fever, phlebitis and nephrotoxicity ${ }^{[3]}$. The serum trough concentration is a useful index that is correlated with the efficacy and safety of vancomycin. Because vancomycin is mainly eliminated via glomerular fil-

\footnotetext{
\# These authors contributed equally to this work.

* To whom correspondence should be addressed.

E-mail luwei_pk@hsc.pku.edu.cn

Received 2016-12-20 Accepted 2017-04-19
}

tration, this therapeutic indictor can be predominantly affected by renal function ${ }^{[4,5]}$. It has been reported that $80 \%-90 \%$ of the vancomycin can be recovered from the urine of adults 24 $h$ after administration ${ }^{[6]}$. In infants and patients with renal dysfunction, the serum trough level of vancomycin may be elevated and elimination decreased ${ }^{[7-9]}$. The elimination halflife $\left(t_{1 / 2}\right)$ of vancomycin is approximately 4 to $6 \mathrm{~h}$ in subjects with normal renal function, but this value is 7.5 days in the patients with renal insufficiency ${ }^{[10,11]}$.

The creatinine clearance $\left(\mathrm{CL}_{\mathrm{Cr}}\right)$ and glomerular filtration rate (GFR) estimated from the Cockcroft-Gault (CG) equation are commonly used to evaluate renal function in clinical practice $^{[12]}$. In recent years, new GFR estimation methods (eg, 
the Modification of Diet in Renal Disease (MDRD) equation ${ }^{[13]}$ and the Chronic Kidney Disease Epidemiology Collaboration (CKD-EPI) equation ${ }^{[14]}$ ) have been proposed. The additions of age, gender, and blood test values and a correction for race to these two equations have been demonstrated to provide more accurate estimations of the GFR than the CG equation in most patient populations ${ }^{[14-17]}$. Although the modified equations outperform the original equation, the applicability of these equations for describing vancomycin pharmacokinetics requires further investigation.

The Bayesian method is regarded as the most efficient approach for vancomycin clinical effectiveness and side-effect monitoring as well as dose adjustment ${ }^{[18,19]}$. This method can be combined with population pharmacokinetics (Pop-PK) to predict the drug concentration profile of an individual ${ }^{[20,21]}$ and has the potential to support individual vancomycin dosage decisions in adults ${ }^{[21,22]}$. Clinically, the target concentration intervention (TCI) has been widely applied and can help maximize clinical benefits ${ }^{[23,24]}$. For TCI, a proper Pop-PK model is required ${ }^{[25,26]}$ and is valuable in highly variable populations that are receiving a drug with a narrow therapeutic window, $e g$, vancomycin ${ }^{[27]}$. TCI focuses on the estimation of the initial dose to achieve the target concentration by calculating the pharmacokinetic (PK) and pharmacodynamic (PD) parameters according to the relevant covariates, such as dosage, treatment duration, and clinical effects during treatment ${ }^{[28]}$.

The objectives of this study were to develop an appropriate Pop-PK model of vancomycin for Chinese adult patients and to compare the influence of various renal function descriptors on the predictability of vancomycin Pop-PK models. This study may benefit individualized vancomycin therapy in Chinese adult patients in the clinic.

\section{Materials and methods}

\section{Patients and data collection}

This study was conducted at the Beijing Hospital, Beijing, China with the approval of the local medical ethics committee. Patients who received continuous infusion of vancomycin (1000 mg q12 h) and were not on renal replacement therapy were eligible for study participation. The patients' demographic and pathophysiological characteristics were collected at the beginning of vancomycin treatment and are presented in Tables 1 and 2. Two hundred fifty-one samples were collected before the next dose (trough serum vancomycin concentration, $C_{\text {min }}$ ), and each patient contributed at least one blood sample. Vancomycin serum concentrations were measured using a method involving the TDx-FLx fluorescence polarization immunoassay analyzer (Abbott Laboratories, Diagnostics Division, Abbott Park, IL, USA). The quantification limit was $2.0 \mathrm{mg} / \mathrm{L}$, and the intra- and inter-assay coefficients of variation were $<4 \%$ over the entire calibrator range $(7-75 \mathrm{mg} / \mathrm{L})$.

\section{Drugs and reagents}

Vancomycin hydrochloride for intravenous administration (Vancocin CP) was obtained from Eli Lilly Japan KK (Seishin Laboratories, Kobe, Japan). The serum concentration of
Table 1. Patient demographic of the model building dataset and validation dataset.

\begin{tabular}{|c|c|c|}
\hline Characteristics & $\begin{array}{l}\text { Model building, } \\
\text { median (range) }\end{array}$ & $\begin{array}{l}\text { Model validation, } \\
\text { median (range) }\end{array}$ \\
\hline № of patients & 160 & 58 \\
\hline Gender M/F (\%) & $106: 54$ & $39: 19$ \\
\hline AGE (year) & $78(42-95)$ & $69(40-90)$ \\
\hline BW (kg) & $65(38-90)$ & $65(45-85)$ \\
\hline $\mathrm{HT}(\mathrm{cm})$ & $170(150-185)$ & $168(155-183)$ \\
\hline $\mathrm{BMI}\left(\mathrm{kg} / \mathrm{m}^{2}\right)$ & $22.31(12.85-36.89)$ & $22.12(17.30-31.25)$ \\
\hline $\mathrm{BSA}\left(\mathrm{m}^{2}\right)$ & $1.75(1.30-2.12)$ & $1.74(1.43-1.98)$ \\
\hline Vancomycin conc/mg.L ${ }^{-1}$ & $18.09(0.80-71.56)$ & $15.61(0.41-44.76)$ \\
\hline Sample per patient & $2(1-17)$ & $2(1-6)$ \\
\hline $\operatorname{ALT}\left(I U \cdot L^{-1}\right)$ & $22(2-250)$ & $23(4-190)$ \\
\hline TBIL $\left(\mu \mathrm{mol} \cdot \mathrm{L}^{-1}\right)$ & $8.55(2-486)$ & $9.5(3.4-90.4)$ \\
\hline DBIL $\left(\mu \mathrm{mol} \cdot \mathrm{L}^{-1}\right)$ & $3.41(0-130)$ & $3.3(1-27.4)$ \\
\hline $\mathrm{TP}\left(\mathrm{g} \cdot \mathrm{L}^{-1}\right)$ & $60.55(25-85)$ & $61(34-88)$ \\
\hline $\operatorname{ALB}\left(g \cdot L^{-1}\right)$ & $30.95(16-45)$ & $32(21-40)$ \\
\hline $\mathrm{S}_{\mathrm{cr}}\left(\mu \mathrm{mol} \cdot \mathrm{L}^{-1}\right)$ & $75(24-893)$ & $68(25-748)$ \\
\hline BUN $\left(\mathrm{mmol} \cdot \mathrm{L}^{-1}\right)$ & $8(1.28-53.15)$ & $8.88(1.81-28.06)$ \\
\hline URIC $\left(\mu \mathrm{mol} \cdot \mathrm{L}^{-1}\right)$ & 225 (23.79-957) & $211(55-528)$ \\
\hline $\operatorname{GLU}\left(\mu \mathrm{mol} \cdot \mathrm{L}^{-1}\right)$ & $5.94(0.89-19.98)$ & $5.8(4.4-18.5)$ \\
\hline AST (IU.L $\left.L^{-1}\right)$ & $28(9-699)$ & $26(7-239)$ \\
\hline $\mathrm{CL}_{\mathrm{Cr}}\left(\mathrm{mL} \cdot \mathrm{min}^{-1}\right)$ & $58.02(5.45-224.0)$ & $73.91(8.48-231.79)$ \\
\hline
\end{tabular}

vancomycin was determined using a fluorescence polarization immunoassay method with a vancomycin protein assay kit (Abbott Laboratories, USA) and a TDx-FLx assay system (Abbott Laboratories, Irving, TX, USA).

\section{Model development}

The model estimations were performed using NONMEM $7^{\circledR}$ (version VII, level 3.0; ICON Development Solutions, Ellicott City, MD, USA) with the FOCEI method. Both interindividual and residual variability were included in the models. Demographic variables of the adult patients, including gender, age, weight, and renal function descriptors, including serum creatinine $(\mathrm{Scr})$, creatinine clearance rate $\left(\mathrm{CL}_{\mathrm{cr}}\right)$, blood urea nitrogen $^{[29]}$, and albumin (ALB), were tested as potential covariates for the PK parameters. The covariates were selected through the method of stepwise forward selection-backward elimination. A covariate was regarded as significant when the addition of the covariate resulted in the OFV decreasing more than $3.84(P<0.05)$, and the exclusion of the covariate resulted in the OFV increasing more than $10.83(P<0.001)$.

The exponential model was used to describe the interindividual variability of the PK parameters according to equation 1.

$P_{\mathrm{i}}=P_{\text {pop }} \times e^{\eta}$

where $P_{\mathrm{i}}$ represents the PK parameter for the $i$ th individual, $P_{\text {pop }}$ is the population typical value of the parameter, and $\eta_{\mathrm{i}}$ is a random variable for the $i$ th individual following a normal distribution with a mean of 0 and a variance of $\omega^{2}$.

It was assumed that the parameters and residual error vari- 
Table 2. Demographic background and physiological and biochemical information of the data ( $n=218$ patients, 251 vancomycin concentrations).

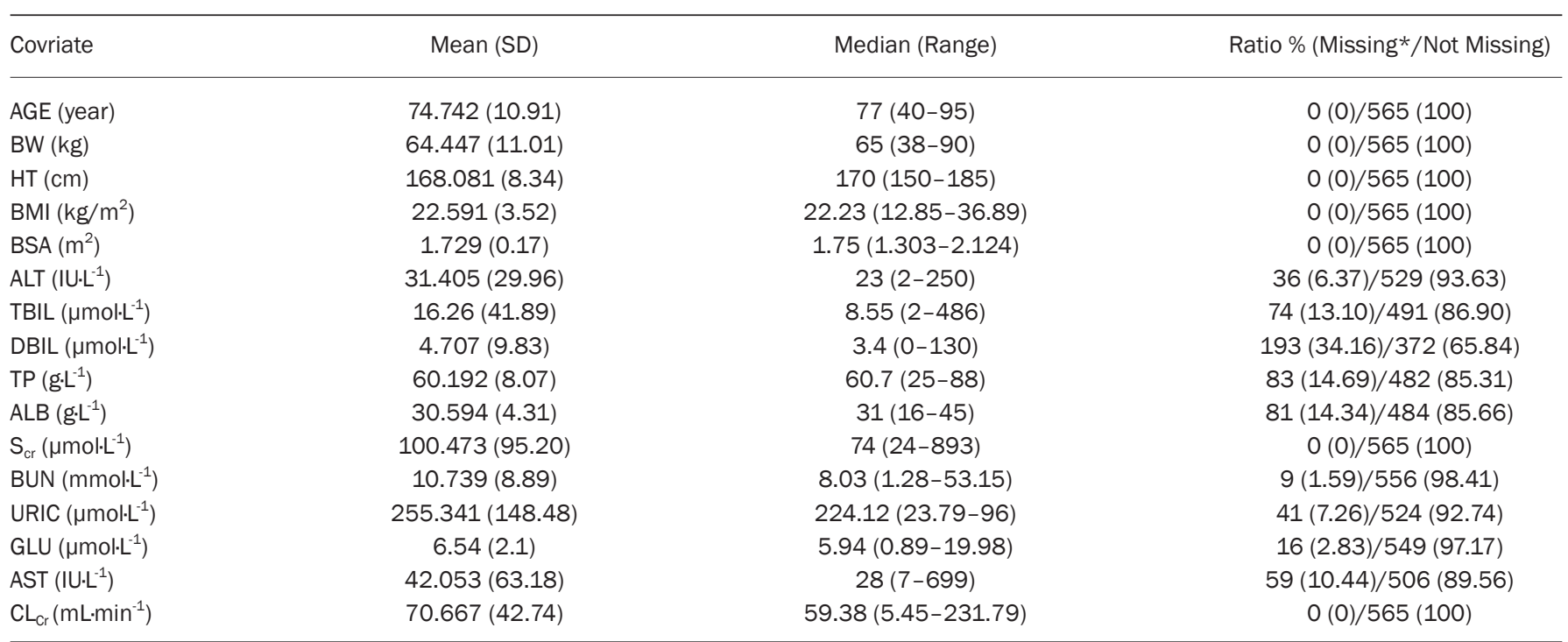

*: We use the mean value to replace the missing value.

ability followed a logarithmic normal distribution, and the residual error model was a combined error model (equation 2).

$C_{\mathrm{Obs}}=C_{\mathrm{Pred}} \times\left(1+\varepsilon_{1}\right)+\varepsilon_{2}$

where $C_{\mathrm{obs}}$ is the observed serum vancomycin concentration, $C_{\text {pred }}$ is the corresponding model predicted concentration, and $\varepsilon_{1}$ and $\varepsilon_{2}$ represent the proportional error and additive error, respectively. The parameters $\varepsilon_{1}$ and $\varepsilon_{2}$ were assumed to follow a normal distribution with a mean of 0 and a variance of $\sigma^{2}$.

The following were continuous covariates:

$P_{\mathrm{i}}=P_{\text {pop }} \cdot\left[1+\theta_{\mathrm{COV}} \cdot\left(\operatorname{Cov}_{\mathrm{i}}-\overline{\operatorname{Cov}_{\mathrm{i}}}\right)\right]$

$P_{\mathrm{i}}=P_{\text {pop }} \cdot\left(\operatorname{Cov}_{\mathrm{i}} / \overline{\operatorname{Cov}}_{\mathrm{i}}\right)^{\theta_{\mathrm{cov}}}$

The following were the non-continuous covariates:

$P_{\mathrm{i}}=P_{\text {pop }} \cdot\left[1+\theta_{\mathrm{COV}} \cdot \mathrm{COV}_{\mathrm{i}}\right]$

$\mathrm{COV}_{\mathrm{i}}$ and $\overline{\mathrm{COV}}$ represent the $i$ th individual values and population mean value of the covariate, respectively. $\theta_{\mathrm{COV}}$ is the calibrator for the parameters.

\section{Test of different renal descriptors}

Creatinine clearance $\left(\mathrm{CL}_{\mathrm{cr}}\right)$ was calculated with the CockroftGault equation $^{[12]}$.

$\mathrm{CL}_{\mathrm{Cr}(\text { Male })}=\frac{(140-\text { Age }) \times \mathrm{WT}}{72 \times \text { Scrmg } / 100 \mathrm{~mL}}$

$\mathrm{CL}_{\mathrm{Cr}(\mathrm{Female})}=0.85 \times \mathrm{CL}_{\mathrm{Cr}(\text { Male })}$

BSA was calculated with equation 8 .
$\mathrm{BSA}=0.007184 \times \mathrm{BW}^{0.425} \times \mathrm{HT}^{0.725}$

Eq (8)

The original MDRD equations were as follows:

$\mathrm{aGFR}_{\mathrm{MDRD}}=186 \times \mathrm{Age}^{-0.203} \times \mathrm{Scr}^{-1.154} \times 0.742($ if female) $\quad$ Eq (9)

$\mathrm{GFR}_{\mathrm{MDRD}}=170 \times \mathrm{Age}^{-0.176} \times \mathrm{Scr}^{-0.999} \times \mathrm{BUN}^{-0.170} \times \mathrm{ALB}^{0.318}$

$\times 0.762$ (if female)

where age is in years, serum creatinine (Scr) is in $\mathrm{mg} / \mathrm{dL}$, blood urea nitrogen ${ }^{[29]}$ is in $\mathrm{mg} / \mathrm{dL}$, and ALB is in $\mathrm{g} / \mathrm{dL}$.

Race is an important determinant of GFR estimation. The performances of the modified MDRD in equation 11 and equation 12 with correction coefficients for Chinese patients have been tested ${ }^{[30]}$.

$\mathrm{aGFRC}_{\mathrm{MDRD}}=186^{-0.203} \times \mathrm{Scr}^{-1.154} \times 0.742($ if female $) \times 1.211 \quad \mathrm{Eq}(11)$

GFR7C $_{\text {MDRD }}=170 \times$ Age $^{-0.176} \times \mathrm{Scr}^{-0.999} \times \mathrm{BUN}^{-0.170} \times \mathrm{ALB}^{0.318} \times 1.233$ $\times 0.762$ (if female)

GFR was standardized by body surface area (BSA) ${ }^{[31]}$, and resulted in the $\mathrm{GFR}_{\mathrm{BSA}}$. $\mathrm{GFR}_{\mathrm{BSA}}$ was calculated according to the equation 13:

$\mathrm{GFR}_{\mathrm{BSA}}=\mathrm{GFR} \times \frac{\mathrm{BSA}}{1.73}$

\section{Model validation}

The ability of the final Pop-PK model to describe the observed data was evaluated by bootstrapping, a visual predictive check (VPC) and goodness-of-fit plots. The VPC and bootstrapping were performed to evaluate the predictive accuracy and stability of the final model, respectively. Using the final model, 1000 data sets that were simulated with the obtained 
final parameter estimates, and the median and 5th and 95th percentiles were calculated ${ }^{[32,33]}$. The adequacy of the model was evaluated by comparing the distribution of observed values with that of the simulated values. The model validations were based on the normalized prediction distribution errors (NPDE) of the predictions with 1000 simulations using PsN (version 4.2.0 $)^{[34,35]}$. The relative standard errors were provided to evaluate the precision of the parameters ${ }^{[36]}$.

The model was also validated by conducting an external validation with a qualified dataset $(n=58)$ using Bayesian feedback technology. Using substitution of $C_{\text {pred }}$ and $C_{\text {obs }}$ into equations 14 and 15, the mean prediction error (MPE) and the mean absolute prediction error $(\mathrm{MAE})^{[2]}$ were calculated. The MPE and MAE were used to evaluate the predictability of the final model.

$$
\begin{aligned}
& \mathrm{MPE}=\frac{1}{N} \sum \frac{\left(C_{\text {Pred }}-C_{\text {Obs }}\right)}{C_{\text {Obs }}} \\
& \mathrm{MAE}=\frac{1}{N} \sum \frac{\left|C_{\text {Pred }}-C_{\text {Obs }}\right|}{C_{\text {Obs }}}
\end{aligned}
$$

\section{Simulation}

Based on the established Pop-PK model, several simulations of different loading dose and maintenance dose regimens were performed to reach the target steady-state trough concentrations of $10-15 \mathrm{mg} / \mathrm{L}$ and $15-20 \mathrm{mg} / \mathrm{L}$. In the final model, $\mathrm{CL}_{\mathrm{Cr}}$ and age were used as the covariates, and both influenced the PK of vancomycin. The range of $\mathrm{CL}_{\mathrm{Cr}}$ values was designated $10-160 \mathrm{~mL} / \mathrm{min}$ (steps of $10 \mathrm{~mL} / \mathrm{min}$ ) according to the range of the data set used for model establishment (5.45-224.0 $\mathrm{mL} / \mathrm{min})$. The age span was designated $30-90$ in steps of 10 years. The preset doses occurred in multiples of $250 \mathrm{mg}$, and the highest dose was $2500 \mathrm{mg}$. To facilitate clinical administration and increase the compliance of the patients, the dosing intervals were designated 8, 12, 24 and $48 \mathrm{~h}$.

\section{Results}

A one-compartment model with first-order absorption was developed to describe the vancomycin concentration-time profile. The final models were described by the following equations:

$$
\begin{array}{ll}
\mathrm{CL}=2.829 \times\left(1+0.00842 *\left(\mathrm{CL}_{\mathrm{Cr}}-80\right)\right) *\left(\frac{75}{\mathrm{Age}}\right)^{0.08143} \times e^{\eta_{1}}(\mathrm{~L} / \mathrm{h}) & \mathrm{Eq}(16) \\
V=52.14 \times e^{\eta_{2}}(\mathrm{~L}) & \mathrm{Eq}(17)
\end{array}
$$

where 2.829 is the typical population value for 75-year-old patients with a $\mathrm{CL}_{\mathrm{Cr}}$ of $80 \mathrm{~mL} / \mathrm{min}$. The value of $0.00842 \mathrm{rep}-$ resents the variation rate constant of $\mathrm{CL}$ as $\mathrm{CL}_{\mathrm{Cr}}$ changed at 1 $\mathrm{mL} / \mathrm{min}$. The value of 0.08143 is the influence coefficient of age on $\mathrm{CL}^{[37]}$. The value 52.14 represents the typical value of the apparent volume of distribution $(V) . \eta_{1}$ and $\eta_{2}$ represent the interindividual variations of $\mathrm{CL}$ and $V$, which followed normal distributions with a mean of 0 and variances of 0.1051 and 0.083 , respectively.

The goodness-of-fit is an important factor for evaluating the reliability of the model. The observed data versus either the population or the individual predicted values were closely distributed around the $y=x$ line, and the trend lines closely coincided with $y=x$, which indicated that the model predictions were in reasonable agreement with the observed plasma concentrations (Figure 1A and 1B). The conditional weighted residuals (CWRES) were randomly and homogenously distributed approximately 0 (Figure $1 \mathrm{C}$ and $1 \mathrm{D})$, and the trend lines closely coincided with the $x$-axis.

Figure 2 presents the median and 10th and 90th percentile prediction intervals ${ }^{[38]}$ from the 1000 VPC simulations with the observed data superimposed. The results suggest that the models fit well with the observed values, and most of the observed data fell within the range of the $80 \%$ confidence inter-

\begin{tabular}{|c|c|c|c|}
\hline \multirow{2}{*}{ Parameters } & \multirow{2}{*}{$\begin{array}{c}\text { Base model } \\
\text { Estimate (RSE\%) }\end{array}$} & \multicolumn{2}{|c|}{ Final Model } \\
\hline & & Estimate (RSE\%) & Median $(95 \% \mathrm{Cl})$ \\
\hline $\mathrm{CL}(\mathrm{L} / \mathrm{h})$ & $2.295(0.024)$ & $2.829(5.73)$ & $2.827(2.57-3.07)$ \\
\hline$\theta_{\text {Cler_CL }}{ }^{a}$ & -- & $0.00842(19.66)$ & $0.00849(0.0054-0.0099)$ \\
\hline$\theta_{\text {Age_CL }^{\mathrm{b}}}$ & -- & $0.8143(53.68)$ & $0.8373(0.313-1.359)$ \\
\hline \multicolumn{4}{|l|}{ Inter-individual variability } \\
\hline IIV_CL (\%) & $52.97(14.49)$ & 32.42 (11.9) & $32.13(24.77-39.87)$ \\
\hline IIV_V (\%) & $22.21(61.41)$ & $28.87(53.82)$ & $31.73(10.94-62.05)$ \\
\hline Residual variability SD $(\mathrm{ng} / \mathrm{mL})$ & $2.795(0.052)$ & $2.647(16.26)$ & $2.578(1.649-3.63)$ \\
\hline CV $(\%)$ & $25.33(0.024)$ & $26.79(14.88)$ & $25.81(13.82-33.43)$ \\
\hline
\end{tabular}
vals of the predictions. The parameter estimates and bootstrap $95 \%$ confidence intervals are presented in Table 3 . A success

Table 3. Pharmacokinetic parameters of three models and bootstrap of mature model.

$\mathrm{CL}$, apparent clearance; $\mathrm{V}$, apparent volume of distribution; $\mathrm{CV}(\%)$, percent coefficient of variation.

a Effect of $\mathrm{CL}_{\mathrm{Cr}}$ on $\mathrm{CL}$, no units, refer to the equation 6 in the 'Methods' section

${ }^{b}$ Effect of Age on CL, no units, refer to the equation 8 in the 'Methods' section 
A

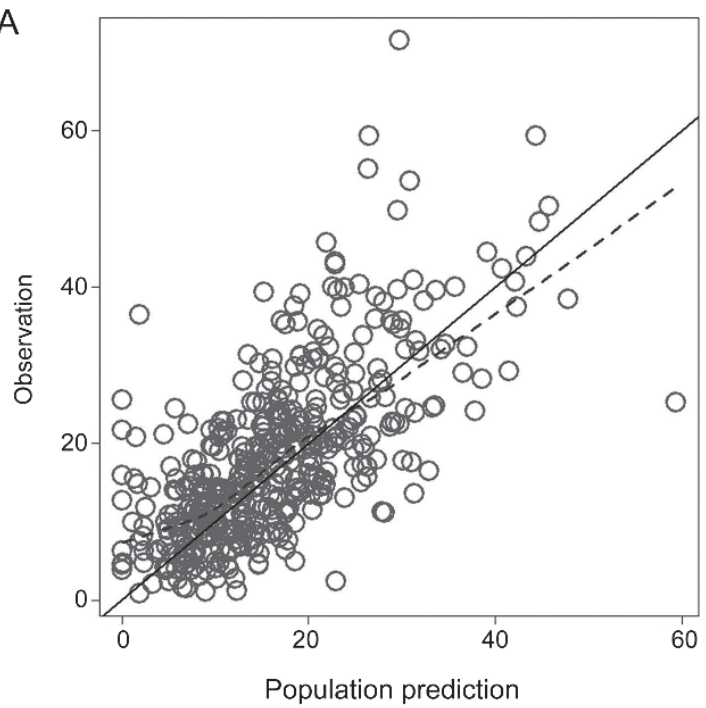

C

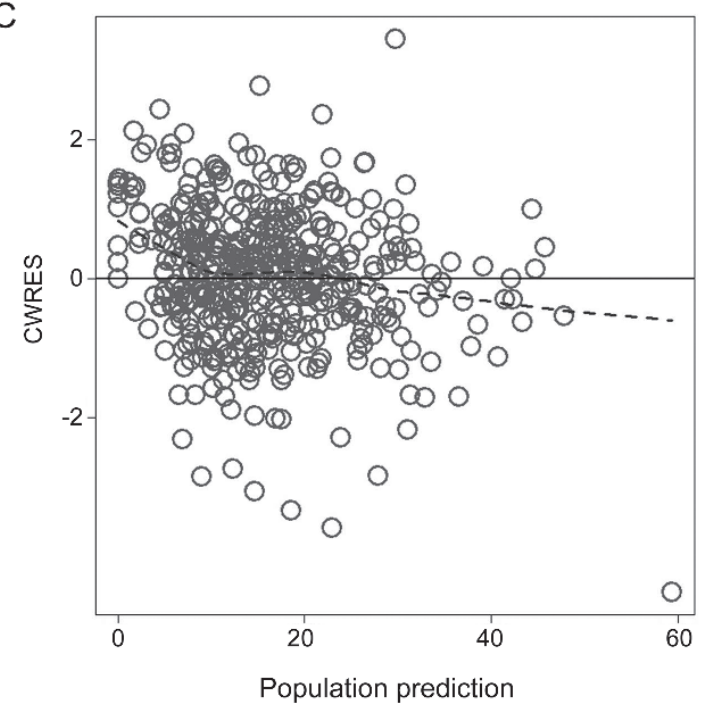

B

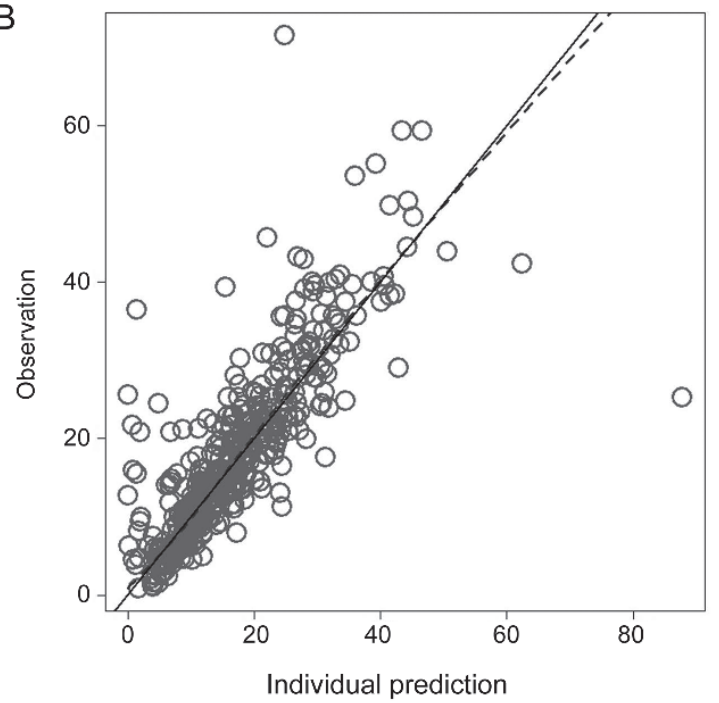

D

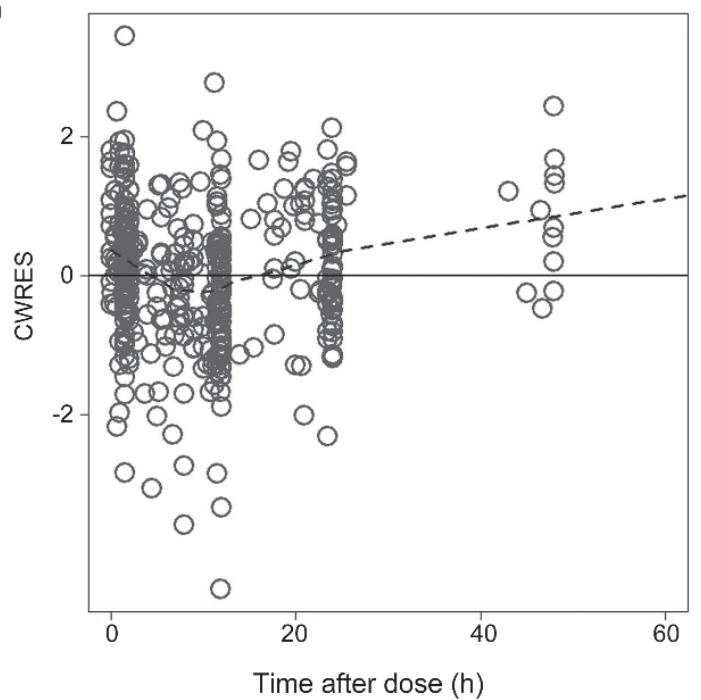

Figure 1. Basic goodness-of-fit plot of the final model. The upper left plot represents the observations versus the population predictions (A). The upper right plot represents the observations versus the individual predictions (B). The lower left plot represents the conditional weighted residuals versus the population predictions $(C)$. The lower right plot represents the conditional weighted residuals versus the time after dose (D). The line in the upper plots is the identical line, and the line in the lower plots is the zero line.

rate of $91.6 \%$ was obtained from the bootstrap analysis.

An external validation using a different renal biomarker was conducted with data from 58 patients, and the results of the verification are provided in Table 4 . Figure 3 illustrates the distributions of the prediction errors from each of the renal function descriptors in the final analyses of the entire patient data sets for both the population and the individual predictions. In the analysis of the validation results, the different renal descriptors were not significantly different from the estimates of the renal functions of the 58 individuals.

According to the simulation results, the initial dosage regimens containing the loading doses and maintenance doses that reached the target steady-state trough concentrations $10-15 \mathrm{mg} / \mathrm{L}$ and $15-20 \mathrm{mg} / \mathrm{L}$ were obtained. The loading dose regimens are provided in Tables $\mathrm{S} 1$ and $\mathrm{S} 2$, and the maintenance dose regimens are provided in Tables S3 and S4.

\section{Discussion}

Because the majority of vancomycin is excreted into the urine in its original form ${ }^{[6]}$, the accuracy of the models for the estimation of renal function may affect the prediction of the serum vancomycin concentration. The purposes of this study were to build population pharmacokinetic models for Chinese adult patients, to investigate the influences of different renal function descriptors on the predictability of the models and to eventually assist in individualizing vancomycin dosage regimens for patients with different levels of renal function.

A one-compartment model with zero-order absorption was 
Table 4. Summary of external evaluation using different renal biomarker.

\begin{tabular}{lcc}
\hline Model & MPE (SD) & MAE (SD) \\
\hline $\mathrm{CL}_{\text {Cr }}$ & $0.023(0.33)$ & $0.22(0.25)$ \\
GFR7 $_{\text {MDRD }}$ & $0.026(0.38)$ & $0.24(0.30)$ \\
$\alpha G F R_{\text {MDRD }}$ & $0.023(0.36)$ & $0.23(0.28)$ \\
GFR7C $_{\text {MDRD }}$ & $0.026(0.38)$ & $0.24(0.30)$ \\
$\alpha$ GFRC $_{\text {MDRD }}$ & $0.023(0.36)$ & $0.23(0.28)$ \\
GFR7 $_{\text {MDRD_BSA }}$ & $0.026(0.36)$ & $0.23(0.278)$ \\
$\alpha_{\text {GFFR }}$ & $0.021(0.35)$ & $0.22(0.26)$ \\
GFR7_BSA $_{\text {MDRD_BSA }}$ & $0.026(0.36)$ & $0.23(0.28)$ \\
$\alpha_{\text {GFRRC }}$ & $0.021(0.35)$ & $0.22(0.26)$ \\
\hline
\end{tabular}

established to characterize vancomycin PK in adult Chinese patients. The estimated typical values of the PK parameters are summarized in Table 4 . All parameters were estimated with good precision (RSE<30\%). The PK of vancomycin has been reported to be influenced by multiple factors, such as renal function, weight, age and gender ${ }^{[39,40]}$. The influences of the available covariates on the PK parameters (primarily clearance) were assessed in the established structural model. In this study, the influences of demographic data, including gender, body weight, age and renal function descriptors, on vancomycin clearance and the volume of distribution were examined using allometric scaling ${ }^{[41]}$. Gender did not significantly affect vancomycin clearance; neither did body weight or height, which is likely due to the narrow ranges of these covariates. The results also indicated that vancomycin clearance was significantly affected by age, which is consistent with previous studies ${ }^{[42,43]}$. It has been suggested that a dosage adjustment for renal function is needed for elderly patients because renal function decreases naturally with increases in age. The goodness-of-fit (Figures 1A-1D) and VPC (Figures 2) results suggested that the final model adequately captured the PK profiles of vancomycin in adult Chinese patients.

A

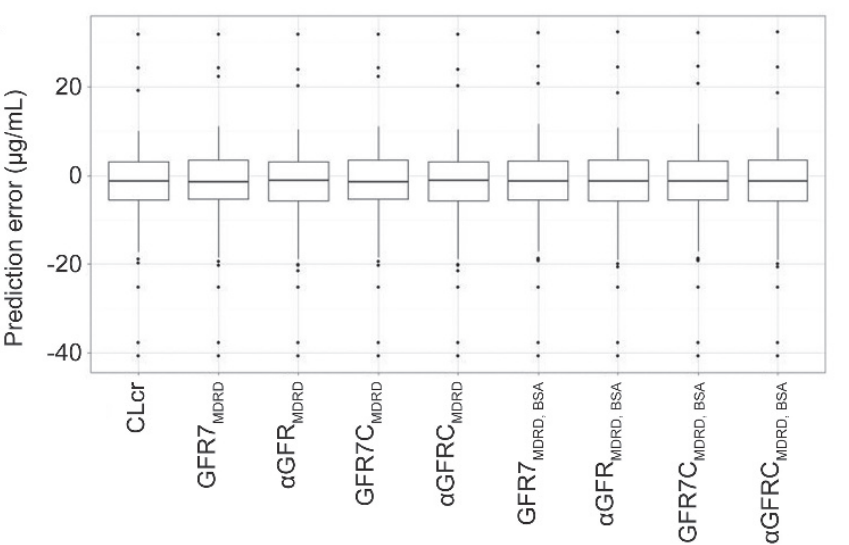

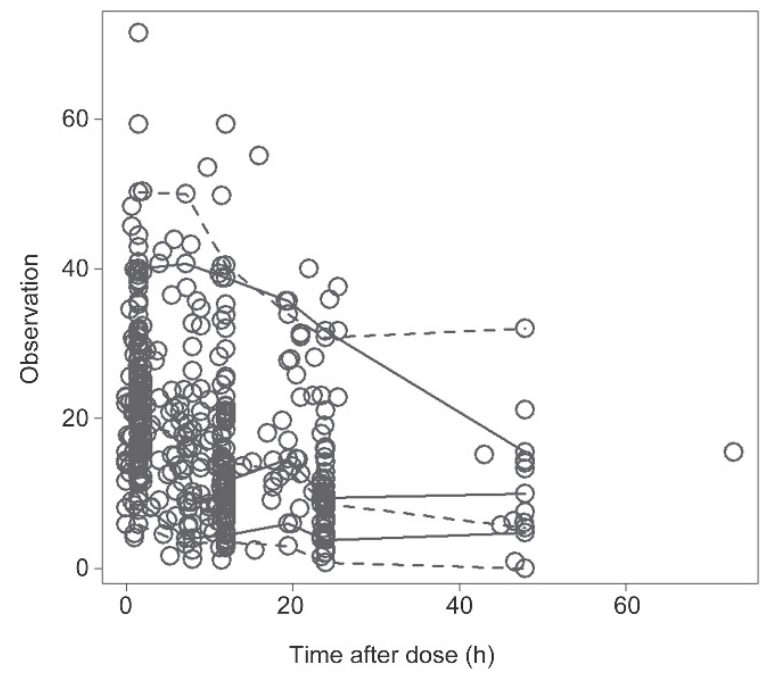

Figure 2. Visual predictive check of the final model of vancomycin. The circles are the observations. The solid lines are the medians of the simulated and observed concentrations, and the dashed lines are the $80 \%$ confidence interval $(10 \%, 90 \%)$ of the predictive and observed vancomycin concentrations. The gray lines are for the observations, and the black lines are for the simulation.

The establishment of an appropriate Pop-PK model is a prerequisite for achieving the vancomycin TCI. Most of the developed vancomycin Pop-PK models for adult patients incorporate the $\mathrm{CL}_{\mathrm{Cr}}$ as estimated from the CG equation into clearance as an important covariate ${ }^{[44]}$. To our knowledge, studies of the influence of GFR on the vancomycin Pop-PK in Chinese populations have rarely been reported. In the present study, we used a modified MDRD equation to estimate the GFR in Chinese adult patients. The original MDRD equations were developed based on Blacks and Caucasians and are not suitable for Asians ${ }^{[30,45]}$. The GFR of patients with near-normal kidney function was underestimated in the original MDRD

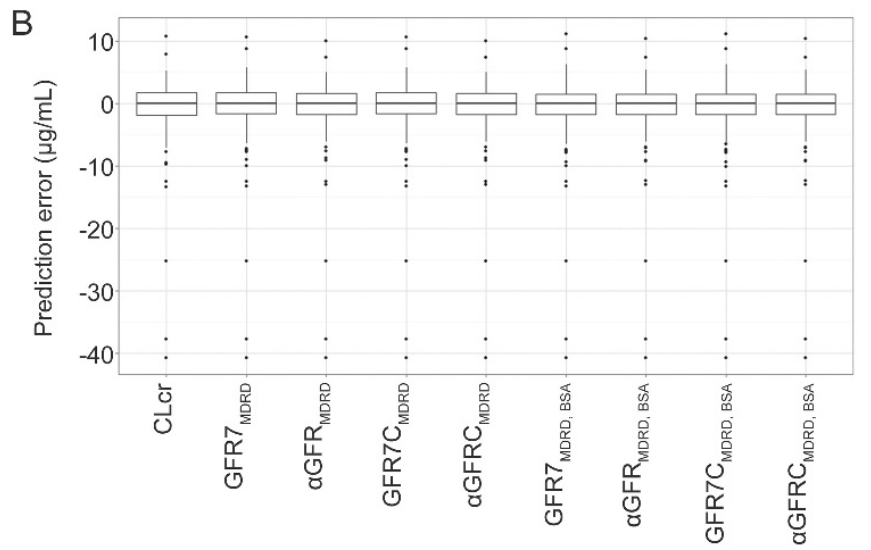

Figure 3. Box plots of the prediction errors from the 9 renal function descriptors. For each box, the central marker is the median, and the edges of the box are the 25th and 75th percentiles. The whisker length is 1.5 times the interquartile range. The dots represent outlier values. The left plot illustrates the population predictions (A). The right plot shows the individual predictions (B). 
equations ${ }^{[5,30,46]}$. The modified MDRD equations exhibited lower bias and greater accuracy than the original MDRD equations when applied to Chinese patients, particularly among patients with nearly normal kidney function.

Appropriate descriptors of renal function are essential to assure the accuracy of vancomycin models. Therefore, the renal function descriptors that best predict the vancomycin PK should be determined and applied. Although the results demonstrated that the renal function descriptors had little influence on the predictability of the vancomycin Pop-PK models, we were unable to identify the reason that the present study did not reveal significant differences in prediction due to these renal function parameters. This lack of differences is probably because the selection of descriptors with regard to renal function using a Pop-PK approach is data-dependent. Accordingly, external evaluation and cross validation among these renal function parameters are necessary for the further evaluation of the established Pop-PK models.

The current vancomycin trough concentration therapeutic window $(5-10 \mathrm{mg} / \mathrm{L})$ used in the clinic can lead to the occurrence of resistance ${ }^{[4]}$. To avoid resistance against vancomycin, the trough concentration ought to reach $10-15 \mathrm{mg} / \mathrm{L}$. When vancomycin trough concentrations reach $10-15 \mathrm{mg} / \mathrm{L}$, the recovery rate of infected patients with the MICs $>1 \mathrm{mg} / \mathrm{L}$ tend to be low. In contrast, the recovery rate of infected patients with MICs $>1 \mathrm{mg} / \mathrm{L}$ can be significantly increased when vancomycin trough concentrations reach $15-20 \mathrm{mg} / \mathrm{L}$. Thus, the initial dosage regimens of vancomycin should be designed to reach the target steady-state trough concentrations of 10-15 $\mathrm{mg} / \mathrm{L}$ and $15-20 \mathrm{mg} / \mathrm{L}^{[48]}$. The principle of selecting the optimal dosage regimens is as follows: the dosage regimens with the lowest administration dose and the minimum drug concentration fluctuations that are also capable of reaching the target steady-state trough concentrations should be selected. Model-based simulation may contribute to the optimization of vancomycin individual dosage regimens in Chinese adult patients and to the reduction of resistance against vancomycin.

The main limitation of this study is the small sample size of our data set. Data from only 160 patients were applied to establish the model, and the data from 58 patients were used in the Bayesian forecasting. Therefore, the results should be generalized carefully, and further evaluation studies should be conducted when more samples are collected. However, the study results may contribute to the achievement of the vancomycin TCI in the clinic.

In conclusion, A Pop-PK model of vancomycin for Chinese adult patients with varying degrees of renal functions that used various renal function descriptors as covariates was established. The external evaluation results suggested that these renal function descriptors may be considered interchangeably in the estimation of vancomycin clearance and did not exhibit significant influences on the predictive capability of the models.

\section{Acknowledgements}

This work was supported by the Research Foundation of
Peking University First Hospital.

\section{Author contribution}

Xi-wei JI, Shuang-min JI, Xiao-rong HE and Wei LU designed the research; Xi-wei JI, Shuang-min JI and Xiao-rong HE performed the research; Xi-wei JI, Shuang-min JI, Xiao ZHU and Rong CHEN analyzed the data; Xi-wei JI and Shuang-min JI wrote the paper.

\section{Abbreviation}

Pop-PK, population pharmacokinetics; NONMEM, nonlinear mixed-effect model; AUC, area under concentration-time curve; CLcr, creatinine clearance rate; ARC, augmented renal clearance; CWRES, conditional weighted residual errors; IIV, inter-individual variability; CI, confidence interval; VPC, visual predictive check; FOCEI, first-order conditional estimation with an interaction option; MIC, minimum inhibitory concentration.

\section{Supplementary information}

Supplementary information is available at the website of Acta Pharmacologica Sinica.

\section{References}

1 Martin JH, Norris R, Barras M, Roberts J, Morris R, Doogue M, et al. Therapeutic monitoring of vancomycin in adult patients: a consensus review of the American Society of Health-System Pharmacists, the Infectious Diseases Society of America, and the Society Of Infectious Diseases Pharmacists. Clin Biochem Rev 2010; 31: 21-4.

2 Rybak M, Lomaestro B, Rotschafer JC, Moellering R Jr, Craig W, Billeter $\mathrm{M}$, et al. Therapeutic monitoring of vancomycin in adult patients: a consensus review of the American Society of HealthSystem Pharmacists, the Infectious Diseases Society of America, and the Society of Infectious Diseases Pharmacists. Am J Health Syst Pharm 2009; 66: 82-98.

3 An SY, Hwang EK, Kim JH, Kim JE, Jin HJ, Jin SM, et al. Vancomycinassociated spontaneous cutaneous adverse drug reactions. Allergy Asthma Immunol Res 2011; 3: 194-8.

4 Capitano B, Frye RF, Matzke GR. Vancomycin. In: Murphy JE editor. Clinical pharmacokinetics: American Society of HealthSystem Pharmacists, Bethesda, MD; 2008. p 329-44.

5 Rule AD, Larson TS, Bergstralh EJ, Slezak JM, Jacobsen SJ, Cosio FG. Using serum creatinine to estimate glomerular filtration rate: accuracy in good health and in chronic kidney disease. Ann Intern Med 2004; 141: 929-37.

6 Lundstrom TS, Sobel JD. Antibiotics for gram-positive bacterial infections. vancomycin, teicoplanin, quinupristin/dalfopristin, and linezolid. Infect Dis Clin North Am 2000; 14: 463-74.

7 de Hoog M, Mouton JW, van den Anker JN. Vancomycin: pharmacokinetics and administration regimens in neonates. Clin Pharmacokinet 2004; 43: 417-40.

8 Zhang $\mathrm{H}$, Wang Y, Gao P, Hu J, Chen Y, Zhang L, et al. Pharmacokinetic characteristics and clinical outcomes of vancomycin in young children with various degrees of renal function. J Clin Pharmacol 2016; 56: 740-8.

9 Yamamoto T, Terakawa H, Hisaka A, Suzuki H. Bayesian estimation of pharmacokinetic parameters of vancomycin in patients with decreasing renal function. J Pharm Sci 2012; 101: 2968-75.

10 Wenk M, Vozeh S, Follath F. Serum level monitoring of antibacterial 
drugs. A review. Clin Pharmacokinet 1984; 9: 475-92.

11 Blowey DL, Warady BA, Abdel-Rahman S, Frye RF, Manley HJ. Vancomycin disposition following intraperitoneal administration in children receiving peritoneal dialysis. Perit Dial Int 2007; 27: 79-85.

12 Cockcroft DW, Gault MH. Prediction of creatinine clearance from serum creatinine. Nephron 1976; 16: 31-41.

13 Imai E, Horio M, Nitta K, Yamagata K, Iseki K, Hara S, et al. Estimation of glomerular filtration rate by the MDRD study equation modified for Japanese patients with chronic kidney disease. Clin Exp Nephrol 2007; 11: 41-50.

14 Kilbride HS, Stevens PE, Eaglestone G, Knight S, Carter JL, Delaney MP, et al. Accuracy of the MDRD (Modification of Diet in Renal Disease) study and CKD-EPI (CKD Epidemiology Collaboration) equations for estimation of GFR in the elderly. Am J Kidney Dis 2013; 61: 57-66.

15 Froissart M, Rossert J, Jacquot C, Paillard M, Houillier P. Predictive performance of the modification of diet in renal disease and Cockcroft-Gault equations for estimating renal function. J Am Soc Nephrol 2005; 16: 763-73.

16 Levey AS, Coresh J, Greene T, Stevens LA, Zhang YL, Hendriksen S, et al. Using standardized serum creatinine values in the modification of diet in renal disease study equation for estimating glomerular filtration rate. Ann Intern Med 2006; 145: 247-54.

17 Levey AS, Stevens LA, Schmid CH, Zhang YL, Castro AF 3rd, Feldman $\mathrm{HI}$, et al. A new equation to estimate glomerular filtration rate. Ann Intern Med 2009; 150: 604-12.

18 Uaamnuichai M, Day RB, Brater DC. Bayesian and least-squares methods for vancomycin dosing. Am J Med Sci 1987; 294: 100-4.

19 Bruno R, Iliadis MC, Lacarelle B, Cosson V, Mandema JW, Le Roux Y, et al. Evaluation of Bayesian estimation in comparison to NONMEM for population pharmacokinetic data analysis: application to pefloxacin in intensive care unit patients. J Pharmacokinet Biopharm 1992; 20: 653-69.

20 Avent ML, Vaska VL, Rogers BA, Cheng AC, van Hal SJ, Holmes NE, et al. Vancomycin therapeutics and monitoring: a contemporary approach. Intern Med J 2013; 43: 110-9.

21 Neely MN, Youn G, Jones B, Jelliffe RW, Drusano GL, Rodvold KA, et al. Are vancomycin trough concentrations adequate for optimal dosing? Antimicrob Agents Chemother 2014; 58: 309-16.

22 Nunn MO, Corallo CE, Aubron C, Poole S, Dooley MJ, Cheng AC. Vancomycin dosing: assessment of time to therapeutic concentration and predictive accuracy of pharmacokinetic modeling software. Ann Pharmacother 2011; 45: 757-63.

23 Hennig S, Norris R, Kirkpatrick CM. Target concentration intervention is needed for tobramycin dosing in paediatric patients with cystic fibrosis--a population pharmacokinetic study. Br J Clin Pharmacol 2008; 65: 502-10.

24 Rajendran SD, Rao YM, Karthikeyan VP. Evaluation of target concentration intervention strategy of gentamicin therapy in a malnourished patient population of south India. Indian J Med Res 2005; 122: 511-7.

25 Holford NH. Target concentration intervention: beyond Y2K. Br J Clin Pharmacol 2001; 52 Suppl 1: 55S-59S.

26 Saleem M, Dimeski G, Kirkpatrick CM, Taylor PJ, Martin JH. Target concentration intervention in oncology: where are we at? Ther Drug Monit 2012; 34: 257-65.

27 De Vriese AS, Vandecasteele SJ. Vancomycin: the tale of the vanquisher and the pyrrhic victory. Perit Dial Int 2014; 34: 154-61.

28 Matthews I, Kirkpatrick C, Holford N. Quantitative justification for target concentration intervention-parameter variability and predictive performance using population pharmacokinetic models for aminoglycosides. Br J Clin Pharmacol 2004; 58: 8-19.

29 Purwonugroho TA, Chulavatnatol S, Preechagoon Y, Chindavijak B, Malathum K, Bunuparadah P. Population pharmacokinetics of vancomycin in Thai patients. ScientificWorldJournal 2012; 2012: 762649.

30 Zuo L, Ma YC, Zhou YH, Wang M, Xu GB, Wang HY. Application of GFRestimating equations in Chinese patients with chronic kidney disease. Am J Kidney Dis 2005; 45: 463-72.

31 Du Bois D, Du Bois EF. A formula to estimate the approximate surface area if height and weight be known. 1916. Nutrition 1989; 5: 30311; discussion 12-3.

32 Karlsson MO, Savic RM. Diagnosing model diagnostics. Clin Pharmacol Ther 2007; 82: 17-20.

33 Efron B, Tibshirani RJ. An introduction to the bootstrap New York; 1993.

34 Lindbom L, Ribbing J, Jonsson EN. Perl-speaks-NONMEM (PsN)--a Perl module for NONMEM related programming. Comput Methods Programs Biomed 2004; 75: 85-94.

35 Brendel K, Comets E, Laffont C, Mentre F. Evaluation of different tests based on observations for external model evaluation of population analyses. J Pharmacokinet Pharmacodyn 2010; 37: 49-65.

36 Shah SM, Ashtikar M, Jain AS, Makhija DT, Nikam Y, Gude RP, et al. LeciPlex, invasomes, and liposomes: A skin penetration study. Int J Pharm 2015; 490: 391-403.

37 Anderson BJ, Allegaert K, Van den Anker JN, Cossey V, Holford NH. Vancomycin pharmacokinetics in preterm neonates and the prediction of adult clearance. Br J Clin Pharmacol 2007; 63: 75-84.

38 Llopis-Salvia P, Jimenez-Torres NV. Population pharmacokinetic parameters of vancomycin in critically ill patients. J Clin Pharm Ther 2006; 31: 447-54.

39 Macedo E, Mehta RL. Measuring renal function in critically ill patients: tools and strategies for assessing glomerular filtration rate. Curr Opin Crit Care 2013; 19: 560-6.

40 Mahmoud MA, Ebid AH, Shouman SA, Ebid EN. Pharmacokinetics of vancomycin in oncology egyptian paediatrics: a dosage adjustment trial. Indian J Pharm Sci 2014; 76: 82-6.

41 West GB, Brown JH, Enquist BJ. A general model for the origin of allometric scaling laws in biology. Science 1997; 276: 122-6.

42 Sanchez JL, Dominguez AR, Lane JR, Anderson PO, Capparelli EV, Cornejo-Bravo JM. Population pharmacokinetics of vancomycin in adult and geriatric patients: comparison of eleven approaches. Int J Clin Pharmacol Ther 2010; 48: 525-33.

43 Guay DR, Vance-Bryan K, Gilliland S, Rodvold K, Rotschafer J. Comparison of vancomycin pharmacokinetics in hospitalized elderly and young patients using a Bayesian forecaster. J Clin Pharmacol 1993; 33: 918-22.

44 Marsot A, Boulamery A, Bruguerolle B, Simon N. Vancomycin: a review of population pharmacokinetic analyses. Clin Pharmacokinet 2012; 51: 1-13.

45 Jafar TH, Schmid CH, Levey AS. Serum creatinine as marker of kidney function in South Asians: a study of reduced GFR in adults in Pakistan. J Am Soc Nephrol 2005; 16: 1413-9.

46 Bertolatus JA, Goddard L. Evaluation of renal function in potential living kidney donors. Transplantation 2001; 71: 256-60.

47 Zhang HW, Wang WQ, Liu Y. Analysis of therapeutic drug monitoring data of vancomysin. Pharm C lin Res 2009; 17: 257-9.

48 Thalakada R, Legal M, Lau TT, Luey T, Batterink J, Ensom MH. Development and validation of a novel vancomycin dosing nomogram for achieving high-target trough levels at 2 canadian teaching hospitals. Can J Hosp Pharm 2012; 65: 180-7. 